https://doi.org/10.48009/1_iis_2011_455-463

Issues in Information Systems

Volume XII, No. 1, pp. 455-463, 2011

\title{
GLOBAL PERSPECTIVE ON RADIO SPECTRUM MANAGEMENT USAGE AND POLICY
}

\author{
S. Srinivasan, Texas A \& M International University, Laredo, srini@tamiu.edu
}

\begin{abstract}
Radio Spectrum is a finite resource that is not exhausted by use but still needs to be managed efficiently for all the wireless communications to succeed. The International Telecommunications Union (ITU) has set out guidelines for world-wide use of radio frequencies. Each country manages this resource by adopting suitable policies. Many new technologies such as the Ultra Wide Band (UWB), Worldwide Interoperability for Microwave Access (WiMax) and Long Term Evolution (LTE) have been introduced recently that use spectra more efficiently. With the introduction of many new services the world-wide demand for additional spectra have grown exponentially. Spectrum resource is managed directly by governments or by government agencies in all the countries. Many governments are now making changes in their policies to make available additional spectra for non-governmental use and realigning other spectra in order to meet the increased demand. In this paper we explore how five industrialized countries United States, United Kingdom, Japan, South Korea, and Singapore - have addressed the demand for new spectra and set policies accordingly. In this discussion we have included how the additional spectra have been allocated using various forms of auctions and identify the revenue generated by such auctions.
\end{abstract}

Keywords: Radio spectrum, Wireless, Spectrum management, Auction, Global, Policy

\section{INTRODUCTION}

Radio spectrum is a finite resource of airwaves that is not exhausted by constant use like other natural resources such as water, coal, and oil. The electromagnetic radiation in the airwaves is measured as a radio frequency using the unit Hertz. Managing the radio spectrum concerns the suitable allocation of radio frequencies for various applications such as cell phones, garage door openers, and aircraft communications. The International Telecommunications Union (ITU), which is an agency of the United Nations, has been setting guidelines for the use of spectrum worldwide. Predating ITU, the radio communications coordination has been going on for over 100 years. ITU has grouped the countries of the world into three regions for administrative purposes. Region 1 covers Europe, Russia, all other countries of the former Soviet Union, Mongolia, Turkey, and Africa; Region 2 covers North America, Central America, South America, Greenland, and the Caribbean; Region 3 covers South Asia, Australia, New Zealand, and the Pacific. ITU guidelines for world-wide use of the frequencies are in the range 3 $\mathrm{kHz}$ to $300 \mathrm{GHz}$. Of these frequencies the band from $300 \mathrm{MHz}$ to $3 \mathrm{GHz}$ is considered prime spectrum because the signals have lower frequencies in this range and consequently they are capable of penetrating walls and moisture filled environments such as tree covered parts of the country. Table 1 below gives the commonly used frequencies for various types of frequency bands.

Table 1. ITU Frequency Band Designations

\begin{tabular}{|l|l|l|}
\hline Symbol & \multicolumn{1}{|c|}{ Designation } & \multicolumn{1}{c|}{ Frequency } \\
\hline MF & Medium Frequency & $300 \mathrm{kHz}$ to $3 \mathrm{MHz}$ \\
\hline HF & High Frequency & $3 \mathrm{MHz}$ to $30 \mathrm{MHz}$ \\
\hline VHF & Very High Frequency & $30 \mathrm{MHz}$ to $300 \mathrm{MHz}$ \\
\hline UHF & Ultra High Frequency & $300 \mathrm{MHz}$ to $3 \mathrm{GHz}$ \\
\hline SHF & Super High Frequency & $3 \mathrm{GHz}$ to $30 \mathrm{GHz}$ \\
\hline EHF & Extremely High Frequency & $30 \mathrm{GHz}$ to $300 \mathrm{GHz}$ \\
\hline
\end{tabular}

In United States, the spectrum allocation responsibility rests with the Federal Communications Commission (FCC) for non-federal government use of spectra and the National Telecommunications and Information Administration 
(NTIA) for federal government use of spectra. In United Kingdom, the Office of Communications (Ofcom) is responsible for managing the use of spectra. In South Korea, the Ministry of Information and Communication manages the spectrum allocation and in Japan, the Ministry of Internal Affairs and Communications manages the same. In Singapore, the Info-Communications Development Authority regulates spectrum allocation and management. Thus, the Spectrum Management Authority (SMA) in each country is either a government department or an agency of the government. In this paper we will follow the convention that 'civilian use' of the spectra would refer to the non-governmental use, except in U.S. In U.S. the federal government is a major user of the spectra and all non-federal government users include all the 50 state governments, local governments, and the first responders such as police, fire, and ambulance. Thus, the civilian use in U.S. is much broader than other countries. Because of the very extensive federal government use of spectra in U.S., the federal government use of the spectra is independently governed by NTIA.

Countries around the world have realized that auctioning spectrum is an excellent way to generate revenue for the government even though it is not the primary motive. Much of the spectrum auction follows the 'command and control' model whereby the regulator places strict rules for spectrum use in order to avoid signal interference with the communication in the neighboring band. Such auctions bring in billions of dollars. For example, the European 3G auction for cellular services fetched over US\$190 billion in 2000. The 3G auction sale in UK netted £22.5 billion in 2000. In U.S., a portion of the newly released analog TV spectrum generated over US\$25 billion in 2008. In UK, Ofcom is currently preparing for the $4 \mathrm{G}$ auction with the plan of providing high speed internet connectivity throughout the country. The spectrum for this comes from the newly released spectrum from the conversion to digital TV. The regulatory bodies use different types of auctions - some exclusive licenses to offer services, some wholesale licenses to few companies who in turn rent out their spectra to many smaller entities. The South Korean government realized the importance of this source of revenue to grow the communications industry and created a new fund called the Information Promotion Fund. This was funded from the auction revenue as well as a small fee generated as a percent of revenue of the communications companies. This fund, estimated at US\$5 billion, has invested in information promotion and thus contributed significantly to South Korea's stature in the world today as the broadband leader.

Since 1990 countries around the world have used auction as the primary means to allocate spectra in a fair way. New Zealand was the first country to use auctions for spectrum allocation. In U.S., FCC started using auctions since 1994, prior to that only lotteries were used for spectrum allocation. Every country is learning from the auction experience of other countries. Based on this factor, Hong Kong, Denmark, Taiwan, and Nigeria insisted on having all bidders participate in the auction. The reason for this approach was to avoid many bidders dropping out close to the auction time and leaving fewer bidders than the number of bands available for auction. Nigeria successfully implemented an Ascending Clock auction in 2001 whereby the minimum price increased with the passage of time during the auction, making the bidders to decide sooner rather than later. Another lesson learned from the recent European auction as well as one of the FCC auctions in 1996 that tied up spectrum in litigation [7] for eight years was that many bidders who bought the spectrum for a high price were unable to raise the capital needed to deploy the services. In order to avoid this from happening, India auctioned some of the spectra with the provision that the winning bidder pays a percentage of the revenue from the use of the spectra. This gives greater incentive for the winning bidder to deploy services quickly. This brief discussion on auction shows the complexity of this process in allocating spectra.

Wireless technology is growing rapidly today. In many parts of Africa as well as in many developing countries the number of wireless customers is far more than the number of landline customers. Advent of technologies such as WiFi (Wireless Fidelity), Ultra Wide Band (UWB), WiMax (Worldwide Interoperability for Microwave Access) and LTE (Long Term Evolution) have contributed to several new applications [5, 12, 13]. WiFi uses the unlicensed ISM band, usually $2.4 \mathrm{GHz}$, and provides wireless internet within an area limited to 300 feet of the base station. WiMax, on the other hand, provides wireless internet service up to 30 miles using bandwidth allocated for this purpose. This service helps rural areas especially where internet service penetration is not high. LTE is emerging in U.S. as the next wave of high speed mobile internet connectivity in the current 4G deployment, with speeds ranging up to $100 \mathrm{Mbps}$ [5]. As a technology LTE has features similar to WiMax but is aimed at the consumer as opposed to 
the service provider as WiMax is geared for. LTEs range and data rate would bring much of the wired communication's applications to mobile communications.

These new applications and the concomitant increase in the number of subscribers world-wide has resulted in the need for additional bandwidth. Countries around the world are coping with this demand in a variety of ways by finding additional spectra. In this paper we will address the debates that have arisen based on these demands and the policies being considered by the regulatory agencies in United States, United Kingdom, Japan, South Korea, and Singapore. We will also include brief remarks on some of these aspects in other countries as they relate to a particular discussion.

\section{SPECTRUM ALLOCATION AND MANAGEMENT}

In this section we will consider the spectrum allocation and management issues from the perspective of U.S., U.K., South Korea, Japan, and Singapore. Among the developed countries in the world, United States has the least amount of spectra allocated for civilian use. According to a report by the Cellular Telecommunications and Internet Association (CTIA) in U.S., the amount of spectra available for civilian use in U.S. is $294 \mathrm{MHz}$ whereas

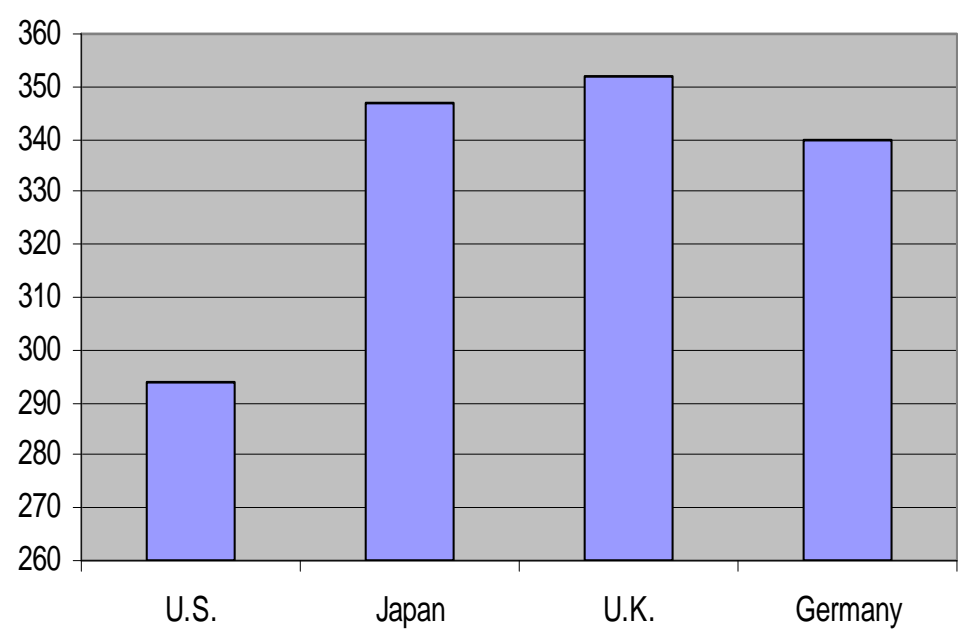

Figure 1. Spectrum Available for Civilian Use

U.K. has made available $352 \mathrm{MHz}$., with an additional $400 \mathrm{MHz}$ to be made available for commercial use by 2010 . Of this additional spectrum, U.K. has made available about $215 \mathrm{MHz}$ by the end of 2007 [9]. Figure 1 illustrates the relative amount of spectra available for civilian use in four of the world's developed countries.

The good thing is that all these countries have plans to allocate more spectra for civilian use in the immediate future to meet the increased demands on the wireless industry. Allocating new spectra is not the only solution. A 2002 study by the Spectrum Policy Task Force in U.S. [1] as well as the 2005 study by McHenry showed that available spectrum is not put to good use [6]. For example, the McHenry study shows that the spectrum use for various applications range from as low as 1 percent to a maximum of 13 percent. This low usage of assigned spectrum wastes a valuable resource. Consequently, efficient use of the available spectra takes on greater significance. The efficient use of spectra not only helps offer more services within the available spectra but also significantly enhances the revenue flow in the economy. According to a study by the Cellular Operators Association of India [10], in 2001 the U.S. economy benefited to the tune of US\$771 billion because of the efficient use of the spectra. Likewise, during the same period the U.K. economy benefited to the tune of $£ 20$ billion. This shows that the regulators should not only focus on making available additional spectra for civilian use but also encourage the introduction of newer technologies which utilize the bandwidth more efficiently. 
The worldwide effort in converting analog TV to digital TV aims to provide higher quality of transmission using lesser amount of bandwidth. In U.S., the Digital TV conversion was completed in June 2009. This conversion released $108 \mathrm{MHz}$ of spectrum for new uses. FCC has auctioned all but $10 \mathrm{MHz}$ of this spectrum for new uses with a vastly different set of rules. The new rules allow flexible use of the spectrum by the winning bidders. In addition, a significant portion of this spectrum was made available for use by the first responders. The terrorist attacks of September 11, 2001 and the Hurricane Katrina disaster of August 2005 brought to light the need for greater interoperability of communication equipments among the various relief agencies at the federal, state, and local levels. So, the FCC is trying to develop an auction plan for the remaining $10 \mathrm{MHz}$ in the upper $700 \mathrm{MHz}$ frequency band that would enable spectrum sharing. Under the spectrum sharing plan the winning bidder for this $10 \mathrm{MHz}$ of spectrum will coordinate with the first responders the equipments used and make available this spectrum to the first responders during periods of emergency. The first responders benefit from lower costs and nationwide interoperability with other emergency providers because of the volume of the equipments that a commercial provider will be able to place in the market. Further, FCC is planning to make available $80 \mathrm{MHz}$ of spectra for Commercial Mobile Radio Services (CMRS) operators in the near future. The Federal government is also working on freeing up some of the frequency for allocation to civilian use. All these actions put together is bound to have a very positive effect on future of high speed wireless communications in U.S. because of the availability of additional spectra. Also, FCC has adopted the flexible use policy in the recent auctions making it more convenient for the service providers to introduce new services.

In U.K., there is a major push towards making available additional spectra for commercial wireless applications. Ofcom has noted the convergence of multiple technologies, coupled with the transition from analog to digital broadcasts, has greatly revolutionized the communications sector [8]. The Digital TV conversion in UK is planned for completion by 2012. Ofcom, in collaboration with the rest of the European Union, is working on harmonizing the use of frequencies so that equipment manufacturers will be able to use the devices in several countries. However, majority of the regulators around the world have not kept up with the convergence of the fixed-line and mobile communications technologies. According to WiMax Forum, "77\% of the regulators still limit $3.5 \mathrm{GHz}$ usage to fixed-only applications" [13]. The United Kingdom has already developed plans to eliminate license restrictions and at the same time increase the available bandwidth for wireless services. Approximately $70 \%$ of the spectrum in the band below $3 \mathrm{GHz}$ will be governed by this new allocation which is also the most coveted band. Just like in U.S. and Australia, U.K. regulators are also moving towards the policy of market forces guiding the allocation of new spectrum. Allocation of spectrum is only one part of the picture. What is driving the rapid growth of wireless applications is content. Content providers such as YouTube and FaceBook have revolutionized the Internet. The newer technologies such as WiMax have the ability to bring such content effectively to the wireless devices such as cell phones and PDAs. These and other popular applications are challenging the principles of policy regulators whose core principles are for "quality, plurality, and standards" [8]. In Europe, much of the debate has been about platform neutrality that would make equipments such as cell phones usable across all countries of Europe, which is not the case now.

In South Korea, The Ministry of Information and Communications controls the spectrum management. The investment in infrastructure of over US $\$ 50$ billion has been facilitated by government policies. As early as 1999 , the penetration of wireless communications exceeded that of land lines. Today, South Korea has the unique distinction of being the world leader in broadband communications. Every 25 people out of 100 have broadband capabilities and that too at a data rate that averages about $8 \mathrm{Mbps}$ where as countries like U.S. average around 1.5 Mbps data rate. With a population of over 49 million, this translates to over three quarters of all households having a broadband connection (ITU). South Korea's regulatory policy has emphasized open access there by enabling the consumer devices to work across all providers. Moreover, the communication has been limited to the $2.4 \mathrm{GHz}$ ISM band only and thus there is no equipment incompatibility. This has created a healthy competition among the major providers. The government has retained control over the four Internet exchanges in the country in order to ensure equal opportunity for all providers. This has translated into the citizens depending very heavily on their mobile handsets for such functions as banking, communication, gaming, and video entertainment. Today, South Korea has the largest deployment of 3G services such as the International Mobile Telecommunications-2000 (IMT-2000). The country now has made significant strides in introducing newer technologies such as CDMA 2000 EV-DO (Evolution Data Only) and EV-DV (Evolution Data and Voice). One potential drawback in South Korea's approach has been on the 
use of domestic standards at several levels. In order to compete in the world market, the country has to migrate to the world standards such as WiMax and W-CDMA (Wideband CDMA) as well. Another innovation in South Korean policy is with regard to the way mobile phone handsets were made affordable to customers. This policy of allowing the operator to enter into a long term agreement with the customer in exchange for a free handset has now been adopted by other countries around the world. Unlike the United States, South Koreans have a limited form of number portability allowed as part of the regulatory control.

Japan's spectrum management authority is the Ministry of Internal Affairs and Communications (MIC). Japan has the world's third largest mobile subscriber population besides China and the United States. In Japan, starting in 2002 the number of cellular phones exceeded that of the land lines (ITU). Consequently the demand for spectrum increased significantly. The MIC developed the policies for introduction of newer services in 2000 and decided on allowing three operators per region because of the limited $60 \mathrm{MHz}$ of spectrum available for such services. Japan leads the world in the number of mobile internet users. Figure 2 below shows the relative position of the countries in our study for mobile internet users [2].

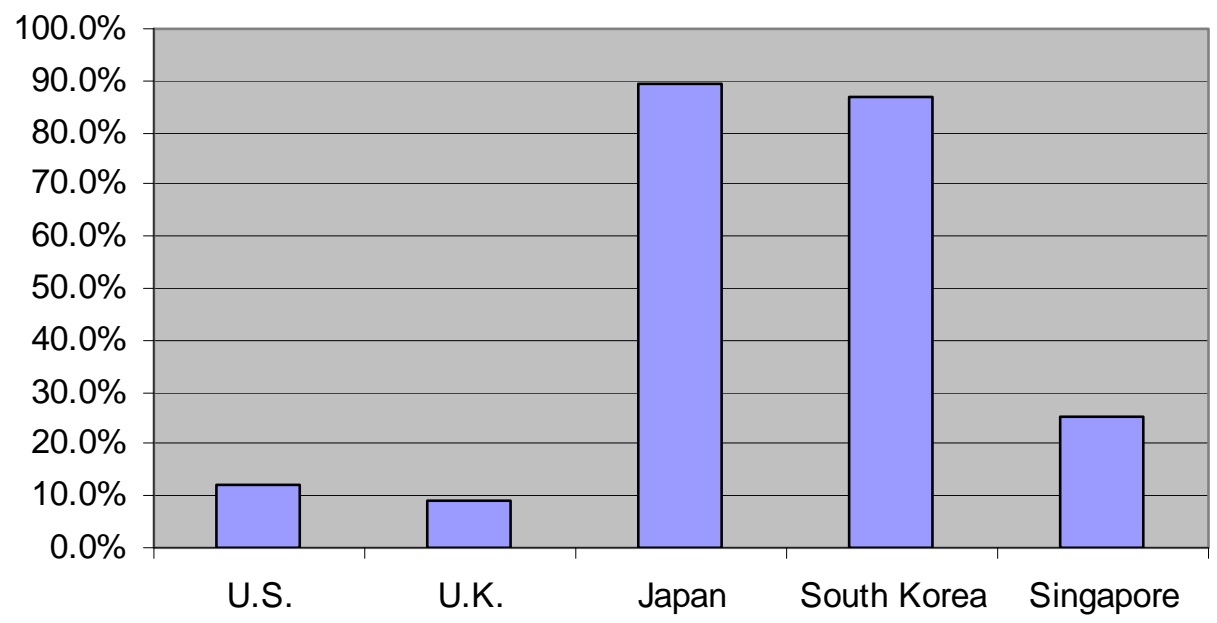

Figure 2. Percentage of Mobile Internet Users

In Japan, the mobile operators and handset manufacturers work in tandem to produce products that will benefit the consumers. This is significant in that in both Europe and U.S., the handset manufacturers control their brands. The close collaboration between the operators and the handset manufacturers has contributed significantly to innovative services. Another significant addition of Japan's mobile services is the research and development for embedding Radio Frequency IDentification (RFID) technology in mobile services.

The last country in our study is Singapore. This city-state in Southeast Asia is a leader in the use of advanced technologies. The spectrum authority for Singapore is Info-Communications Development Authority (IDA). IDA is responsible for allocating spectra for both public and private sectors. IDA works in collaboration with the Media Development Authority (MDA) which is responsible for regulating the broadcasters. In 2000, the government launched Infocomm21 project to develop Singapore as the world's information communication capital. This project is now followed by the Connected Singapore initiative "to create new business opportunities, consumer value and cultural experiences" (ITU). One novel feature of Singapore's wireless initiative is the creation of Mobile Clubs in schools and junior colleges as a collaborative venture of the institutions and wireless industry sponsors. IDA has released the $2.3 \mathrm{GHz}$ and $2.5 \mathrm{GHz}$ spectra for wireless broadband access, with new entrants to the market getting a higher share of the bandwidth than incumbents. These licenses carry greater flexibility for the operators in the choice of technology or the coverage area. IDA has released the $3.5 \mathrm{GHz}$ spectrum for the WiMax technology just like several other Asian countries. In order to promote much wider coverage and deployment of WLAN services, 
IDA is favoring a license-exempt policy. The predominant wireless communication technology deployed in Singapore is W-CDMA. In Singapore, the number of mobile subscribers started exceeding the land line subscribers in 2000. Another important policy decision of IDA that has contributed to the growth of mobile subscribers is the number portability. Among Singaporeans the Short Messaging Services (SMS) has been the most popular wireless service. This is true in the rest of the world as well as Figure 3 shows that SMS traffic is in the trillions of messages. The SMS service in the U.S. is known as texting.

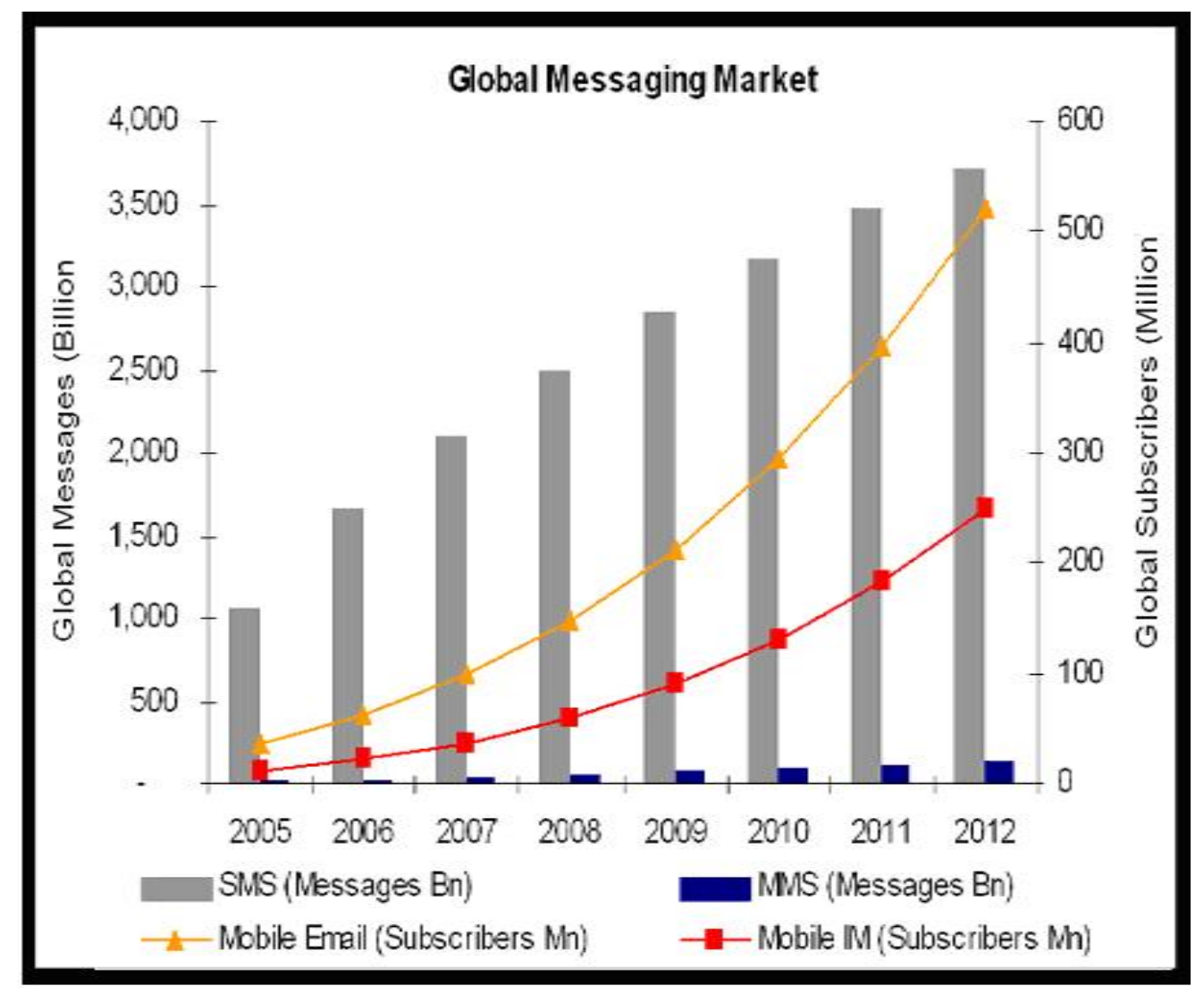

Figure 3. SMS Usage Chart Worldwide

Given the limited geographic area and the small population (approximately 4.3 million), Singapore is in a good position to try new types of wireless services. With this in mind, IDA has promoted "intelligent" services such as consultation for skin care as opposed to just "dumb" services such as email and web browsing (ITU). The "intelligent" services are subscription services for a small fee as they are personalized for the individual user.

In this section we have considered some of the basic features of spectrum management, the policy implications, introduction of emerging technologies, and novel services specific to a country. The main observation is that each of these countries have realized the importance of keeping regulations less of a "command and control" and let market forces dictate the demand for services. All these countries have already allocated additional spectra for broadband services and plans are in the works to enhance this allocation further as the demand continues to grow.

\section{NEWER WIRELESS TECHNOLOGIES}

In the previous section we noted that in order to meet the growing demand for new wireless services, the Spectrum Management Authorities are making available additional spectra, allow flexible use of existing spectra, and encourage efficiency in spectral use. On the spectral efficiency front the leading technologies are spread spectrum, 
software defined radios, and ultra wideband (UWB). Spread spectrum operates by splitting the signals into smaller chunks and transporting them over multiple channels instead of over the same channel. Also, the signals travel for a short period of time. As noted earlier, the allocated spectrum bands are not heavily used. So there are idle times in the use of the allocated spectrum. With spread spectrum technology one could use several of the unused channels without interfering with existing communication. This is considered an overlay technology.

Software defined radios, also known as Cognitive radios, choose idle spectrum and use that for transmitting signals. Unlike a legacy radio channel which uses the same channel whenever needed, the spectrum use is dynamic. Thus, this new technology makes efficient use of the spectrum without requiring any new bandwidth. Ultra wideband technology is the newest of these technologies and is yet to be introduced in many countries. UWB signals travel for very short durations of time (nanoseconds) over a very large range of frequencies in burst format [12]. The channels are chosen dynamically. This is considered an underlay technology. UWB signals have the added advantage that it can penetrate through ground to detect hidden objects such as explosives. On the commercial side, UWB is capable of providing wireless services to play music directly from a cell phone on a surround sound system. Likewise, one could transmit a picture for printing in a printer directly from a camera without any physical wires. The only restriction of UWB is the limited coverage area where it can operate. However, given the nature of applications where it could prove very useful, distance is not a limiting factor. Another new technology is WiMax that we introduced earlier. Many countries have already recognized the importance of WiMax and have allocated mostly the 3.5 GHz frequency for such services.

\section{COMPARATIVE VIEW}

In this section we will look at the rapid growth of wireless technologies and how the various countries are coping up with allocating additional spectra. The commonly used spectra in U.S. for day to day activities are listed in Table 2 below.

Table 2. Common Frequency Bands for Public Services.

\begin{tabular}{|l|l|}
\hline Services Offered & Bandwidth Used \\
\hline Garage door opener, Alarm systems & $40 \mathrm{MHz}$ \\
\hline Cordless phone & 40 to $50 \mathrm{MHz}, 900 \mathrm{MHz}, 2.4 \mathrm{GHz} .5 .8 \mathrm{GHz}$ \\
\hline Baby monitor & $49 \mathrm{MHz}$ \\
\hline Cell phone & 824 to $829 \mathrm{MHz}$ \\
\hline Air traffic control & $960 \mathrm{MHz}$ to $1.215 \mathrm{GHz}$ \\
\hline Global Positioning System (GPS) & 1.227 to $1.575 \mathrm{GHz}$ \\
\hline
\end{tabular}

For popular applications such as cordless phone and GPS, the same frequencies are used worldwide. Regulators around the world mostly follow the lead of FCC in setting policy guidelines. In this connection it is worth noting that the FCC has market-oriented flexible-use policies in several auctions of spectra. Internationally ITU is responsible for allocating spectra where as the national governments are responsible for assigning specific spectra for designated services. Governments mostly use the 'command and control' model in auctioning spectra. This means that the winning bidder is given exclusive use of the spectrum with strict usage rules. Any deviation from the planned usage must be approved by the SMA. Also, the regulators are increasingly using block assignments because block assignments can be less restrictive as long as the interference levels are low. Blocks are created for specific services such as cellular or broadcast TV. Another trend is to look for ways to protect the adjoining spectra from interference. The four common types of interference considered are:

1. Common interference - unwanted energy due to emissions, radiation, etc

2. Harmful interference - signals that interfere with radio navigation service

3. Permissible interference - observed or predicted interference

4. Accepted interference - permissible interference at an agreed upon higher level 
Another important observation by ITU is that the availability of license-exempt spectrum stimulates innovation in products and services. This point was emphasized earlier in section 2 when we looked at the offerings from the various counties. According to a Swedish report in 2004, alternative spectrum management methods such as the introduction of license-exempt bands have proven very effective in lowering entry thresholds for smaller businesses. Yet another reason for having open access, service neutral, shared bands is for enabling entrepreneurial services to be introduced. It may be cost prohibitive for licensing an entire band for testing new services. Moreover, consumers may not know what services they would want until they see them. The classic example in this regard is the advent of Internet. It may be time now to change the regulatory mindset from "Anything that is not explicitly permitted is prohibited" to "Anything that is not explicitly prohibited is permitted." This radical change is suggested for two reasons:

- the landscape that has opened up with the new technologies

- the large number of teenagers and young adults who have embraced these new features

The world-wide growth of mobile broadband services is expected to reach 3 billion subscribers by 2010 according to a recent Gartner study. Steve Largent, President of CTIA, in his keynote address pointed out that in U.S. the number of wireless subscribers has reached 81 percent of the population and increasing steadily [3[. Moreover, these users are sending over one billion SMS messages daily. In financial terms, these services were projected to generate US\$133 billion in 2007. This growth trend is not limited to U.S. only as the data in Table 3 shows [4].

Table 3. World's Top 10 Emerging Mobile Growth Markets

\begin{tabular}{|l|l|l|l|}
\hline Country & $\begin{array}{l}\text { New } \\
\text { subscribers } \\
\text { in 2006 (in } \\
\text { millions) }\end{array}$ & $\begin{array}{l}\text { Total } \\
\text { subscribers } \\
\text { in 2006 (in } \\
\text { millions) }\end{array}$ & $\begin{array}{l}\text { Percent } \\
\text { increase } \\
\text { over } \\
\text { Dec 2005 }\end{array}$ \\
\hline India & 73.56 & 149.5 & 97 \\
\hline China & 67.68 & 461.08 & 17.2 \\
\hline Pakistan & 28.9 & 48.29 & 147 \\
\hline Russia & 26.12 & 151.92 & 21 \\
\hline Indonesia & 23 & 65 & 38.6 \\
\hline Ukraine & 19.03 & 49.21 & 63.1 \\
\hline Brazil & 13.7 & 99.92 & 15.9 \\
\hline Bangladesh & 12 & 21.76 & 135 \\
\hline Nigeria & 11.4 & 30 & 38 \\
\hline Vietnam & 10 & 22.5 & 80 \\
\hline
\end{tabular}

\section{CONCLUSION}

The growth of wireless services is expected to grow at a rapid rate and the only way to facilitate this growth is by the efficient use of available bandwidth and allocation of additional bandwidth. Regulators around the world are developing policies that would support the use of license-exempt bands in which many providers could co-exist. This approach of regulators have opened up new applications such as in-home entertainment using high data rates. Srinivasan [11] describes these applications using technologies that are faster than UWB, WiMax and LTE. The important thing to note is that this growth in use is primarily driven by young users who understand the need for sharing information. This growth has also been beneficial for countries' economies. It is really gratifying to note that this growth cuts across all countries thereby significantly reducing the divide between the rich and the poor. 


\section{REFERENCES}

1. FCC. (2002). http://hraunfoss.fcc.gov/edocs_public/attachmatch/DOC-228542A1.pdf

2. ITU. (2005). Workshop on Ubiquitous Network Societies, Apr. 6-8, Geneva.

3. Largent, S. (2007). CTIA Wireless I.T. \& Entertainment 2007, Oct. 23-25, San Francisco.

4. Lightreading. (2007). http://www.lightreading.com

5. LTE. (2011). http://www.3gpp.org/LTE

6. McHenry, M. (2005). NSF Spectrum Occupancy Measurements Project Summary. http://www.sharedspectrum.com/inc/content/measurements/nsf/NSF_Project_Summary.pdf

7. NextWave. (2004). http://www.internetnews.com/xSP/article.php/3343541

8. Ofcom. (2006). http://www.ofcom.org.uk/research/commsdecade/introduction/

9. Personal Communication. (2007). Cellular Telecommunications \& Internet Association (CTIA), Sept.

10. Ramachandran, T. V. (2004). http://www.itu.int/osg/spu/stn/spectrum/spectrum_resources/general_resources/Ramachandran_URSI.pdf

11. Srinivasan, S. (2011). An Assessment of Technologies for In-Home Entertainment, IEEE $20^{\text {th }}$ Int'l. Conf. on Computer Communications and Networks, Maui, Hawaii, August.

12. UWB. (2011). http://www.wimedia.org/en/index.asp

13. WiMax. (2011). http://www.wimaxforum.org/

Note: All web links were accessed on 6/21/11 